\section{Continuing medical education practices of community-based and university-affiliated anaesthetists in Ontario}

Frederick A. Burrows MD FRCPC, David W. Fear MD FRCPC
To remedy the lack of information about the continuing medical education (CME) practices of anaesthetists, we designed a survey to define and compare the CME activities of specialist anaesthetists in community-based and university-affiliated practices: 463 members of the Canadian Anaesthetists' Society in the Province of Ontario (263 community-based and 200 university-affiliated (University of Toronto) anaesthetists). Data from 304 (65.6\%) respondents (172 community-based and 132 university-affiliated anaesthetists) were analyzed by nonparametric analysis (statistical significance $P<0.05$ ). Most respondents spent between two to four hours per week on $C M E$ activities. Journal reading was the most commonly used method to obtain CME and was perceived to be the most efficient of the methods surveyed $(P<0.05)$. Formal teaching, including seminars, workshops, and annual society meetings, although the second most commonly used technique to obtain CME, was considered as effective as journal reading. Instructional media techniques were the least commonly used and considered the least effective $(P<0.05)$. Most community-based and university-affiliated anaesthetists obtained CME by a variety of techniques; of all respondents, $77 \%$ have no formal method of assessing their learning needs and $88 \%$ would consider participation in a formalized learning needs assessment programme.

\section{Key words}

EDUCATION: continuing, medical, anaesthesia.

From the Department of Anaesthesia, The Hospital for Sick Children and The Higher Education Group, The Ontario Institute for Studies in Education, University of Toronto, Toronto, Ontario, Canada.

Supported in part by a grant from the Faculty Committee on Continuing Education, University of Toronto.

Address correspondence to: Dr. Frederick A. Burrows,

Department of Anesthesia, The Children's Hospital, 300

Longwood Avenue, Boston, Massachusetts, USA 02115.

Accepted for publication I2th February, 1993.
Pour remédier au manque d'information sur l'éducation médicale continue (EMC) des anesthésistes, nous avons élaboré une étude descriptive et comparative des activités de formation médicale d'anesthésistes de pratique privée et diuniversitaire. Ont fait partie de létude 463 anesthésistes (263 de pratique privée et 200 affiliés de l'université de Toronto). Nous avons reçu des réponses de 304 (65,6\% du total) ainsi répartis (172 de pratique privée et 132 universitaires). Ces données ont été étudiées par analyse non-paramétrique (signification statistique $P<0,05$ ). La plupart des répondants passent de deux à quatre par semaine en activité d'EMC. La lecture personnelle de revues médicales est la méthode la plus commune de formation et est perçue comme la plus efficace des méthodes $(P<0,05)$. L'enseignement formel, comprenant séminars, ateliers et réunions annuelles de sociétés, bien qu'au deuxième rang des activités d'EMC privilégiées, est considéré comme aussi efficace que la lecture personnelle. Les techniques d'enseignement médiatiques sont les moins utilisées et considérées commes les moins efficaces $(P<0,05)$. La plupart des membres des deux groupes utilisent une variété de méthodes d'EMC. Parmi les répondants $77 \%$ ne s'appuient sur aucune méthode formelle d'évaluation de leurs besoins et $88 \%$ conviendraient de participer à des études qui leur permettraient de les déterminer.

The new mission statement from the Royal College of Physicians and Surgeons of Canada emphasizes the maintenance of competence through continuing medical education (CME). ${ }^{1}$ The proposed maintenance of competence system (MOCOMP) is a pilot project that embodies important principles: it is voluntary; it recognizes a diversity of styles for enhancing skills, knowledge and attitudes; it must be acceptable to physicians; and it must be credible to the public and to regulatory agencies. The proposed framework includes evidence of CME such as self-directed education, learning objectives based on peer evaluation and scholarly contributions. ${ }^{2}$

The term continuing education tends to be used for educational activities that are conducted at or beyond the post-secondary level ${ }^{3-6}$ and implies some form of 
learning that advances from a previously established level of accomplishment to extend and amplify knowledge. ${ }^{6}$

Physicians participate in CME to fulfill two basic needs: to be apprised of new developments in medicine and to enhance the quality of care they provide to their patients and, in some American states, to maintain licensure or professional status. Continuing medical educational activities chosen by physicians should meet their educational needs in a cost-effective manner, suit their busy schedules, conform to their preferred learning methods, and meet their educational needs, both actual and perceived. $^{7}$

The purpose of this study was to determine and to compare the CME activities and the personal learning needs assessment programmes of community-based vs university-affiliated specialist anaesthetists in Ontario.

\section{Methods}

A survey instrument (questionnaire format) developed specifically for this project was mailed, with a covering letter that explained the nature and importance of the study, to 463 practising specialist anaesthetists selected from the membership list of the Canadian Anaesthetists' Society for the Province of Ontario. The study population consisted of 263 randomly selected community-based anaesthetists and the $2 \mathrm{CO}$ university-affiliated (University of Toronto) specialist anaesthetists. For the purposes of this study a community-based situation was defined as:

... a practice situation in the Province of Ontario where, as a practising anaesthetist, an individual is working in a non-teaching hospital with a nonuniversity-affiliated Department of Anaesthesia.

Since several questions related directly to the anaesthetists' continuing professional development activities and the time accorded to them, we thought that anonymity was important to encourage accurate responses. Those physicians surveyed were asked to return the questionnaire within three weeks; responses were accepted until data analysis began. A reminder was sent at the end of two weeks.

The questionnaire included both open- and closedended questions designed to study five issues. The first section was designed to determine whether there was any correlation between the duration of anaesthetic practice and involvement in continuing professional development activities. The second considered the type of continuing professional development activities respondents preferred and their perception of the efficiency of these activities. The third explored the methods respondents used to keep their knowledge current: all were asked to describe their programme, if they had one; in addition, they were asked to describe the mechanism they used to identify their learning needs. Those who indicated they had none were asked if they would consider participating in a continuing professional development needs assessment programme (if one were available). The fourth section was designed to identify institutional barriers to participation in continuing professional development.

The responses to all these questions were expected to yield information about the fifth issue, the differences between the CME practices and needs of anaesthetists in community and academic environments. Developing a picture of the differences between the two groups' extent of participation in continuing professional development activities and methods of determining learning needs is of particular interest to continuing professional development planners.

\section{Data analysis}

Descriptive statistics were used to analyze and present demographic data; the $t$ statistic to compare proportions. Bonferroni correction for multiple comparisons was applied as indicated. Correlation analysis was used to determine whether statistically significant associations occurred between specific variables. Chi-squared $\left(\chi^{2}\right)$, phi $(\phi)$ coefficient, contingency coefficient and Cramer's V were used in the case of nominal level variables. The Pearson product moment correlation coefficient $(r)$ was calculated for interval level variables. Statistical significance was accepted as $P<0.05$.

\section{Results}

A total of $304(65.6 \%)$ of 463 surveys were returned. One hundred and seventy-two (65.4\%) of the 263 community-based anaesthetists and $132(66.0 \%)$ of the 200 university-affiliated anaesthetists responded to the survey $(P=$ NS).

The respondents included recent graduates with less than one year's experience to anaesthetists with greater than 32 yr experience. The mean ( $\pm S D)$ number of years of anaesthetic practice among the community-based anaesthetists was $14.9( \pm 10.8) \mathrm{yr}$ and among the universityaffiliated anaesthetists, $12.0( \pm 8.6)$ yr $(P=0.01)$. All responding anaesthetists indicated they were involved in professional development activities: community-based anaesthetists spent $3( \pm 1)$ hours per week whereas university-affiliated anaesthetists spend $4( \pm 2)$ hours per week $(P=0.01)$. Linear regression analysis comparing the number of hours per week spent on continuing professional development with the duration of anaesthetic practice demonstrated no significant decrease in CME activity with increasing years of anaesthetic practice for either the community-based anaesthetist $(P=0.44)$ or university-affiliated anaesthetists $(P=0.07)$. 
TABLE I Continuing medical education activity of community-based and university-affiliated anaesthetists

\begin{tabular}{|c|c|c|c|c|c|c|}
\hline \multirow[b]{3}{*}{ Type of CME } & \multicolumn{6}{|c|}{ Response } \\
\hline & \multicolumn{2}{|l|}{ Never } & \multicolumn{2}{|c|}{ Sometimes } & \multicolumn{2}{|c|}{ Frequently } \\
\hline & Com & Univ & Com & Univ & Com & Univ \\
\hline Journals & 0 & 0 & 23 & 19 & 140 & 111 \\
\hline \multicolumn{7}{|l|}{ Instructional media } \\
\hline - Cassette tapes & 58 & 63 & 65 & 43 & 32 & 12 \\
\hline - Video tapes & 42 & 66 & 106 & 49 & 3 & 0 \\
\hline - Telemedicine & 103 & 100 & 37 & 12 & 19 & 1 \\
\hline \multicolumn{7}{|l|}{ Formal teaching } \\
\hline - Lectures & 7 & 2 & 107 & 72 & 38 & 56 \\
\hline - Seminars & 14 & 8 & 103 & 75 & 33 & 40 \\
\hline - Formal courses & 1 & 5 & 97 & 82 & 61 & 42 \\
\hline
\end{tabular}

$\mathrm{CME}=$ continuing medical education; $\mathrm{Com}=$ community-based anaesthetists; Univ $=$ university-affiliated anaesthetists.

Numbers represent the number of respondents who utilized the various modes of obtaining CME and their frequency of use.

TABLE II Efficiency of continuing medical education activities of community-based and university-affiliated anaesthetists

\begin{tabular}{lccccc}
\hline & \multicolumn{2}{l}{ Response } & & \\
\cline { 2 - 3 } \cline { 5 - 6 } Type of CME & Com & & & No \\
\cline { 2 - 3 } \cline { 5 - 6 } & & & Com & Univ \\
\hline Journals & 151 & 125 & & 7 & 0 \\
Instructional media & & & & \\
- Cassette tapes & 81 & 53 & & 53 & 29 \\
- Video tapes & 70 & 52 & & 47 & 32 \\
- Telemedicine & 33 & 27 & & 64 & 44 \\
Formal teaching & & & & \\
- Lectures & 138 & 120 & & 11 & 1 \\
- Seminars & 133 & 112 & & 10 & 3 \\
- Formal courses & 127 & 118 & 14 & 6 \\
\hline
\end{tabular}

$\mathrm{CME}=$ continuing medical education; $\mathrm{Com}=$ community-based anaesthetists; Univ $=$ university-affiliated anaesthetists.

Numbers represent the response to the Yes/No quesiton as to whether the individual found the activity to be an efficient means of obtaining CME.

Of the CME methods that are in use (Table I), reading journal articles was most common overall. There was no difference in the frequency of use of journals between the university-affiliated and community-based anaesthetists $(P=0.902)$. Many respondents commented that journals have the advantages of being easily accessible and relatively inexpensive, and allowing great flexibility in the use of the time available for professional development. The use of audiocassette tapes was greater in the community-based population $(63 \%)$ than in the university-affiliated population $(47 \% ; P=0.012)$. The use of videotaped teaching aids was more common among community-based anaesthetists (72\%) than among university-affiliated anaesthetists $(43 \%)(P<0.001)$. Telemedicine was least commonly used for $\mathrm{CME}$ activities: $32 \%$ of community-based anaesthetists and $11.5 \%$ of university-affiliated anaesthetists indicated they had used this form of CME. The proportion of community-based anaesthetists using formal lectures as a source of CME was equal to that of university-affiliated anaesthetists (95.4\% vs $98.5 \%$ ), but formal lectures were used more frequently by the university-affiliated population $(P=$ 0.003 ). There was no difference in the proportion of respondents using seminars $(P=0.13)$ and those using formal courses $(P=0.12)$ for CME between the groups.

When we questioned the perceived efficiency of the various CME methods (Table II), journal articles were reported to be a highly useful source of CME. Compared with university-affiliated anaesthetists, a small number of community-based anaesthetists (7 of 158) reported they did not find journals a useful way of obtaining CME (4.4\%; $P=0.02$ ). The most common complaint was that many of the articles were too scientific and not relevant to their daily clinical practice. Of the respondents using audiocassette and videotapes as sources of CME, there was no difference in the responses between those who were university-affiliated and those community-based: both were deemed efficient sources of CME $(P=0.41)$. The perceived advantages of these techniques included the wide range of topics they covered and their frequent clinical orientation. Seventy-one (42\%) of the respondents to the question about the efficiency of telemedicine were university-affiliated anaesthetists and 97 (58\%) were community-based anaesthetists. There was no significant difference in the responses between the two groups ( $P$ $=0.59$ ). In both groups the responses indicated that telemedicine was not an efficient method for obtaining CME 
TABLE III Anaesthesia meetings attended in the years 1990-1991 by community-based and universityaffiliated anaesthetists

\begin{tabular}{|c|c|c|c|c|c|c|}
\hline \multirow[b]{3}{*}{ Meeting } & \multicolumn{6}{|c|}{ Number of respondents attending } \\
\hline & \multicolumn{2}{|l|}{1990} & \multicolumn{2}{|l|}{1991} & \multicolumn{2}{|c|}{ Both 1990 \& 1991} \\
\hline & Com & Univ & Com & Univ & Com & Univ \\
\hline Provincial OMA/CAS meetings & 20 & 12 & 13 & 8 & 47 & 8 \\
\hline CAS annual meeting & 22 & 17 & 32 & 16 & 27 & 29 \\
\hline Academy of Medicine & 5 & 12 & 8 & 8 & 57 & 55 \\
\hline ASA annual meeting & 9 & 24 & 14 & 9 & 13 & 14 \\
\hline IARS annual meeting & 5 & 7 & 8 & 4 & 2 & 5 \\
\hline
\end{tabular}

Com $=$ community-based anaesthetists; Univ $=$ university-affiliated anaesthetists; OMA $=$ Ontario Medical Association; CAS = Canadian Anaesthetists' Society; ASA = American Society of Anesthesiologists; IARS = International Anesthesia Research Society.

Numbers represent absolute number of respondents.

TABLE IV Satisfaction by attendees of meetings* providing continuing medical education experience

\begin{tabular}{|c|c|c|}
\hline & \multicolumn{2}{|c|}{ Number of satisfied respondents } \\
\hline & $\begin{array}{l}\text { Community- } \\
\text { based } \\
\text { anaesthetists }\end{array}$ & $\begin{array}{l}\text { University- } \\
\text { affiliated } \\
\text { anaesthetists }\end{array}$ \\
\hline Provincial OMA/CAS meetings & 76 & 27 \\
\hline CAS annual meeting & 98 & 73 \\
\hline Academy of Medicine & 61 & 57 \\
\hline ASA annual meeting & 64 & 80 \\
\hline IARS annual meeting & 22 & 30 \\
\hline
\end{tabular}

OMA $=$ Ontario Medical Association; $\mathrm{CAS}=$ Canadian

Anaesthetists' Society; ASA = American Society of Anesthesiologists; IARS = International Anesthesia Research Society.

* Responses represent those who find the meetings to be a satisfactory source of CME but were not limited to those who attended the 1990 or 1991 meetings referred to in Table III.

$(P=0.042)$. Comments included complaints that many of the presentations were uninteresting or unclear and that there were fewer opportunities to interact than at many lectures or seminars. Lecture presentations were perceived as an efficient form of CME by 258 (96\%) of the 270 respondents to this question. A small number of community-based anaesthetists (11 of 138), however, did not find the lecture format an efficient form of CME and this was different from university-affiliated anaesthetists ( 1 of $121 ; P<0.001$ ). Concerns expressed included too few opportunities to ask questions of the speakers and lack of clarity and clinical relevance of the presentation. Many of the community-based respondents also referred to their difficulty in attending these professional development activities because of their inconvenient locations. The seminar format for $\mathrm{CME}$ was thought to be efficient by both university-affiliated and communitybased anaesthetists.
Of the anaesthesia meetings surveyed (Table III), the Provincial Section on Anaesthesia of the Ontario Medical Association/Ontario Division of the Canadian Anaesthetists' Society regional meetings for 1990 and 1991 were attended by $36 \%$ of all respondents; $74 \%$ of these were community-based anaesthetists and $26 \%$ universityaffiliated anaesthetists $(P=0.02)$. The Canadian Anaesthetists' Society Annual Meeting and The Academy of Medicine meeting $(P=0.002)$ were each attended by $31 \%$ of respondents: there was no difference in attendance between university-affiliated and communitybased anaesthetists $(P=0.18$ and $P=0.253$, respectively). The American Society of Anesthesiologists Annual Meeting, attended by $18 \%$ of respondents, was equally attended by university-affiliated and communitybased anaesthetists $(P=0.099)$. The annual meeting of the International Anesthesia Research Society was attended by $7 \%$ of respondents. There was no difference in the attendance between university-affiliated or community-based anaesthetists $(P=0.226)$.

When the same question of perceived efficiency for CME was applied to these various anaesthesia-related meetings (Table IV), there was no significant difference in the perceived efficiency of the various meetings nor was there a difference between the two groups of anaesthetists, with one exception. The Provincial Ontario Medical Association/Canadian Anaesthetists' Society meetings were not perceived to be an efficient form of CME by the university-affiliated anaesthetists but were thought to be efficient by community-based anaesthetists $(P<0.001)$. From respondents' open-ended comments, both groups' poor attendance at the International Anesthesia Research Society annual meeting appeared to relate to the lack of satisfactory CME offerings.

There was no difference between the number of respondents in both groups who believed that weekly (or monthly) anaesthesia rounds were adequate professional 
development $(P=0.199)$. Many expressed the opinion that the rounds were quite variable in quality (within a single institution) and although some rounds were considered a useful educational experience other rounds were thought to be a waste of time.

A number of anaesthetists in both groups indicated the lack of an organized personal CME programme $(P$ $=0.002$ ). For those who had such a programme, reading review materials in journals or attending continuing medical education courses appeared to be popular. Seventyseven percent (235 of 304) of respondents admitted to having no mechanism for identifying their CME needs $(P<0.001)$, and $88 \%$ (266 of 304$)(P<0.001)$ of all respondents would consider using a method to identify their CME requirements.

In both the university-affiliated and community-based groups of anaesthetists, a greater number suggested that there was sufficient time during their working day to obtain CME. This proportion was greater in the community-based (139 of 172 respondents) than in the university-affiliated (76 of 132 ) group ( $81 \%$ vs $58 \% ; P$ $<0.001$ ). The most commonly stated reason for inability to obtain professional development during the working day was a heavy clinical load, a greater concern of university-affiliated than community-based anaesthetists. A second consideration was the financial impact of using potential income-generating time for professional development activities.

The open-ended comments indicated several other barriers to involvement in continuing professional development. Some mentioned a lack of institutional encouragement for involvement in continuing professional development and family or other personal barriers. Community-based anaesthetists stated that distance of travel to sites of CME programmes was frequently a limiting factor. Both groups commented on the financial impact of using potential income-generating time for professional development activities. There were three respondents who demonstrated attitudinal barriers by characterizing all attempts at continuing professional development as a waste of time.

\section{Discussion}

There are approximately 725 specialist anaesthetists in the Province of Ontario (exact figure not available). We surveyed 463 (approximately 64\%) of these specialist anaesthetists. The $65.7 \%$ response to our survey, with equal responses from the community-based and universityaffiliated (University of Toronto) anaesthetists $(65.5 \%$ vs $66 \%$ ), can be considered representative of the population studied. A response rate of $60 \%$ is considered necessary to ensure representative conclusions for a population surveyed. ${ }^{8}$
The fact that community-based anaesthetists had more years of experience than university-affiliated anaesthetists, but spent less time per week on professional development appears to support previous work by Amos. ${ }^{9}$ She demonstrated a decrease in professional development activities with increasing age and experience. However, linear regression analysis of age vs hours of professional development per week for both groups did not demonstrate a decrease in professional development activities with years of anaesthetic practice. Unlike other professional groups, ${ }^{9}$ professional development activities among anaesthetists are maintained from the time of completion of postgraduate training.

A greater proportion of community-based anaesthetists was satisfied with the time made available during their normal working hours for CME than were universityaffiliated anaesthetists. Consequently, professional development activities in universities, scheduled during normal working hours, are not likely to be as accessible to all anaesthetists as those scheduled outside of normal working hours.

The community-based and university-affiliated anaesthetists were equally divided about the adequacy of the weekly (or monthly) anaesthesia department rounds as a source of professional development. This would seem to imply that many participating anaesthetists do not consider these rounds to be of adequate quality. This response was surprising since these rounds are designed to educate and update, as well as serve as a source of mortality and morbidity review and quality assessment in many hospitals. The negative response from such a large proportion of respondents indicates a failure of these rounds to carry out their mandate and should be of interest to the MOCOMP programme directors who have accepted such rounds for MOCOMP credits.

Journal reading is the most frequent CME activity anaesthetists use (Table I). This result is not surprising. Journals were considered to be a satisfactory source for continuing medical education (Table II). However, a greater proportion of community-based than universityaffiliated anaesthetists considered journals to be an unsatisfactory source of continuing professional development.

Instructional media techniques, although not frequently used by either group, were more commonly used by community-based than university-affiliated anaesthetists (Table I). Overall, they were considered an efficient source of CME by those who did use them (Table II). Of greatest interest was the negative response to telemedicine. Both groups considered this technique, which was the least frequently used of all the techniques surveyed, an inefficient source of professional development. This was surprising since telemedicine is a live production that 
permits interaction between the participant and the speaker. ${ }^{10}$ The stated criticisms of telemedicine included the lack of access to the speaker during the presentation to ask questions, poor quality of the slide presentations, poor presentation of material, and presentations of material not perceived to be clinically useful. Telemedicine was developed as a method to provide reviewed and updated clinically relevant topics to anaesthetists in peripheral communities. The results of this survey suggest that, as it is currently practised, this method is not meeting its mandate and requires reassessment.

Formal teaching techniques (lectures, seminars) were used by similar proportions of community-based and university-affiliated anaesthetists, but more frequently by the latter group (Table I). The seminar format, with its greater opportunity for group interaction, was considered an adequate and efficient form of continuing professional development by the greater proportion of both groups of anaesthetists.

The Canadian Anaesthetists' Society Annual Meeting and the Academy of Medicine meetings were the most frequently attended meetings, and both were perceived to be efficient sources of continuing professional development (Tables III and IV). The Canadian Anaesthetists' Society Annual Meeting contains major CME components: refresher courses, clinical workshops and, more recently, problem-based learning workshops. The local Academy of Medicine meetings (often with speaker and dinner provided under corporate sponsorship at no charge) provide formal lectures with a strong clinical component. The Provincial Section on Anaesthesia of the Ontario Medical Association/Ontario Division of the Canadian Anaesthetists' Society meetings were attended by and perceived as more efficient by a greater proportion of community-based anaesthetists than universityaffiliated anaesthetists. These meetings have always been directed to the clinical anaesthetist and the programmes are designed to meet these needs.

The barriers to participation in CME activities identified in this study have been reported in previous studies on continuing education. ${ }^{11-13}$ Deterrents to continuing education have been classified as situational deterrents (those beyond personal control such as cost, family constraints and work constraints); dispositional deterrents (those based on personal attitudes or dispositions towards participation, including disengagement and perceived lack of benefits), as well as institutional barriers (problems with location and timing, lack of interesting or relevant offerings, procedural problems related to enrollment and lack of information regarding available CME activities).

The anaesthetists surveyed indicated a lack of any formal objective method for determining their true learning needs. However, an overwhelming percentage $(88 \%)$ of all respondents would consider participating in such an assessment, if it were available. Currently, anaesthetists rely upon material published in journals and other publications to provide them with CME and direction for their continuing professional development. No mechanism for determining true learning needs $s^{7,14}$ is used to guide editors of journals.

The continued ability of physicians to practice good medicine is determined to a large extent by their interest in and ability to identify their own high-priority learning needs. Self-perceived needs are of great importance because motivation is a key fact in ensuring the success of educational programmes. Participation and subsequent behavioural change can only be ensured when learners recognize their own unique needs and adopt the programme goals for themselves. ${ }^{15,16}$ In addition, the determination of perceived needs is more easily accomplished and acceptable than the determination of true needs. Evaluation of significant improvement in performance is, however, more difficult when learning needs and goals are subjectively determined. Although objectively determined true learning needs appear to be ideal in theory and facilitate measurement of effectiveness, they require observations or the collection of data by third parties, a process that is threatening to learners and tends to inhibit or prevent participation. The determination of true learning needs requires that criteria be set and standards established based on the recommendations of experts. Medical auditing of patient records and precourse testing are examples of efforts to determine true learning needs.

The educational merit of many of the present forms of continuing medical education can be criticized on the following basis: (1) a lack of evidence to link educational input to clinical behavioural change, (2) limited emphasis given to defining participants' needs clearly (needs assessment), (3) teacher-dominated transfer of facts rather than active learner participation and (4) an episodic rather than a continuing educational experience. ${ }^{17}$ The results of the present study suggest that re-education of the physician population will be necessary to change the manner in which continuing medical education is obtained, although the results do suggest a willingness to try newer techniques.

Four factors involving the nature of the study and its participants that potentially limit this study must be addressed. First, this study was based on the results obtained from a survey. The goal of any survey is to obtain as high a response as possible to ensure that it is representative of the whole population. Research, however, has demonstrated that individuals with strong ideas or opinions are more likely to respond to surveys and may skew the results unless the total response is high; the 
higher the response rate, the better the conclusions reached. ${ }^{8,18}$

Second, since the survey was applied to two specific populations of anaesthetists working in Ontario and the accessibility of continuing professional development activities in this province may be different from that in other provinces, the results of this survey are applicable only to this population. Any attempt to extend the results to and draw conclusions about other populations of anaesthetists may not be appropriate.

Third, since some anaesthetists surveyed may work in a subspeciality of anaesthesia (e.g., pain control), the CME activities of these respondents may differ from those of other members practising in more general anaesthesia. To overcome this problem, however, we would have risked respondents' anonymity and thus, possibly, the response rate.

Fourth, although previous studies have indicated that participants in continuing adult education can be distinguished from non-participants on the basis of their differing socio-demographic and socio-economic characteristics, ${ }^{11,19-21}$ this was not a factor in our study. We considered all respondents socio-demographic and socioeconomic equals.

In conclusion, the CME activities and the personal learning needs assessment techniques of communitybased and university-affiliated anaesthetists in the Province of Ontario have been defined and compared. Minimal differences were identified; many of these may relate to deficiencies in CME planning. The study identifies deficiencies in anaesthetists' ability to determine their true learning needs and indicates their willingness to participate in a formal assessment of their learning needs to help determine the appropriate direction of their CME activities.

\section{Acknowledgement}

This paper was prepared with the assistance of Medical Publications, The Hospital for Sick Children, Toronto, Ontario.

\section{References}

1 The Royal College of Physicians and Surgeons of Canada. Maintenance of competence system (Brochure). Ottawa, The Royal College of Physicians and Surgeons of Canada, 1990.

2 Last J. Maintenance of competence. Annals of the Royal College of Physicians and Surgeons of Canada 1991; 24: 7-8.

3 Campbell DD. Adult education as a field of study and practice. Strategies for development (Brochure). Vancouver: The Center for Continuing Education, The University of
British Columbia, and the International Council for Adult Education, 1977.

4 Houle CO. Continuing Learning in the Professions. San Francisco: Jossey-Bass Publishers, 1980.

5 Schroeder $W L$. Adult education defined and described. In: Smith RM, Aker GF, Kidd JR (Eds.). Handbook of Adult Education. New York: MacMillan, 1970; 25-43.

$6 \mathrm{McClusky} \mathrm{HW}$. The coming of age of lifelong learning. Journal of Research and Developmental Education 1974; 7: 97-107.

7 Baylon GJD, Chung $F$. The continuing medical education needs of anaesthetists. Can J Anaesth 1992; 39: 643-8.

8 Dillman DA. Mail and Telephone Surveys: The Total Design Method. New York: John Wiley \& Sons, 1978.

9 Amos SS. Continuing professional education: a case study of engineers in the Ottawa Valley. Thesis, University of Toronto, 1987.

10 Dunn EV, Acton H, Conrath D, Higgins C, Bain H. The use of slow-scan video for CME in a remote area. Journal of Medical Education 1980; 55: 493-5.

11 Cross KP. Adults as Leamers. San Francisco: Jossey-Bass, 1981.

12 Johnstone JWC, Rivera RM. Volunteers for Learning: A Study of the Educational Pursuits of American Adults. 2nd ed., Chicago: Aldine, 1984.

13 Scanlan CS, Darkenwald GC. Identifying deterrents to participation in continuing education. Adult Education Quarterly 1984; 34: 155-66.

14 Clark AJM. Continuing medical education is as important as patient care. (Editorial) Can J Anaesth 1992; 39: 637-40.

15 Laxdal OE, Jennett PA, Wilson TW, Salisbury GM. Improving physician performance by continuing medical education. Can Med Assoc J 1978; 118: 1051-8.

16 Weinberg $A D$, Ullian L, Richards WD, Cooper P. Informal advice- and information-seeking between physicians. Journal of Medical Education 1981; 56: 174-80.

17 Escovitz GH, Davis D. A bi-national perspective on continuing medical eduation. Acad Med 1990; 65: 545-50.

18 Polit DF, Hungler BP. Nursing Research: Principals and Methods. 3rd ed., Philadelphia: J B Lippincott, 1987.

19 Carp A, Peterson $R$, Roelfs P. Adult learning interests and experiences. In: Cross KP, Valley JR (Eds.). Planning Nontraditional Programs. An Analysis of the Issues for Postsecondary Education. San Francisco: Jossey-Bass, 1974.

20 Shipp T, McKenzie LR. Adult learners and non-leamers: demographic characteristics as an indicator of psychographic characteristics. Adult Education 1981; 31: 187-98.

21 Barton PE. Worklife Transitions: The Adult Learning Connection. New York: McGraw-Hill, 1982. 